\title{
DmOAZ, the unique Drosophila melanogaster OAZ homologue is involved in posterior spiracle development
}

\author{
Anne Krattinger • Nanaë Gendre • Ariane Ramaekers • \\ Nicola Grillenzoni • Reinhard F. Stocker
}

Received: 9 June 2006 / Accepted: 9 January 2007 / Published online: 15 February 2007

(C) Springer-Verlag 2007

\begin{abstract}
In this paper, we study DmOAZ, the unique Drosophila melanogaster homologue of the OAZ zinc finger protein family. We show partial conservation of the zinc finger organization between DmOAZ and the vertebrate members of this family. We determine the exon/intron structure of the $d m O A Z$ gene and deduce its open reading frame. Reverse transcriptase-polymerase chain reaction analysis shows that $d m O A Z$ is transcribed throughout life. In the embryo, strongest DmOAZ expression is observed in the posterior spiracles. We suggest that $d m O A Z$ acts as a secondary target of the $A b d-B$ gene in posterior spiracle development, downstream of cut and ems. In a newly created loss-of-function mutant, $d m O A Z^{93}$, the "filzkörper" part of the posterior spiracles, is indeed structurally abnormal. The $d m O A Z^{93}$ mutant is a larval lethal, a phenotype that may be linked to the spiracular defect. Given the $d m O A Z^{93}$ mutant as a new tool, the fruit fly may provide an alternative model for analyzing in vivo the functions of OAZ family members.
\end{abstract}

Keywords $\mathrm{C}_{2} \mathrm{H}_{2}$ zinc finger transcription factor. OAZ protein family . Drosophila melanogaster . $d m O A Z$ mutant $\cdot$ Spiracle development

Communicated by P. Simpson

Electronic supplementary material The online version of this article (doi:10.1007/s00427-007-0134-7) contains supplementary material, which is available to authorized users.

A. Krattinger $\cdot$ N. Gendre $\cdot$ A. Ramaekers $\cdot$ N. Grillenzoni $\cdot$

R. F. Stocker $(\square)$

Department of Biology, University of Fribourg,

Ch. du Musée 10,

CH-1700 Fribourg, Switzerland

e-mail: Reinhard.Stocker@unifr.ch

\section{Introduction}

The OAZ (O/E-associated zinc finger protein) family of proteins was recently identified as part of the $\mathrm{C}_{2} \mathrm{H}_{2}$ type zinc finger (ZF) superfamily of transcription factors (Knight and Shimeld 2001). Vertebrate OAZ members are characterized by 29-30 ZF domains, which are organized in clusters allowing interaction with either DNA or protein (Tsai and Reed 1997, 1998). OAZ members have been shown to interact with the Olf/EBF transcription factor family (Tsai and Reed 1997) as well as with the BMP-Smad signaling pathway (Hata et al. 2000). Distinct ZF clusters in $\mathrm{OAZ}$ are used in a mutually exclusive manner, participating either in Olf/EBF or BMP-Smad signaling.

To study a developmental role of putative OAZ homologues in Drosophila, we focused on a simple tissue model, i.e., the embryonic and larval posterior spiracles, which previously had served to analyze the genetic basis of differentiation and morphogenesis ( $\mathrm{Hu}$ and Castelli-Gair 1999). The posterior spiracles are functional during the entire larval life, whereas the anterior pair becomes functional only during the second larval instar (Whitten 1980). The two main structures comprising the posterior spiracles, i.e., the stigmatophore and the spiracular chamber, are easily identifiable. The stigmatophore is a dorsal protrusion on the larval tail; the spiracular chamber contains a thin cuticular thread, the "filzkörper", that may function as an air filter (Manning and Krasnow 1993).

On top of the genetic cascade controlling posterior spiracle development appears to be the homeotic gene $A b d-B$ (Sanchez-Herrero et al. 1985). Ectopic $A b d-B$ expression may induce ectopic filzkörper structures and associated spiracular hairs in thoracic and abdominal segments (Lamka et al. 1992; Castelli-Gair et al. 1994). Downstream of $A b d-B$, five early target genes [sal, cut ( $c t$ ), 
empty spiracles (ems), klumpfuss (klu), and nubbin (nub)] and four secondary target genes [engrailed (en), grain (grn), trachealess (trh), and grainy head (grh)] were identified (Hu and Castelli-Gair 1999; Hombria and Lovegrove 2003). Whereas sal, en, and grn are implied in stigmatophore development, the remaining genes are involved in spiracular chamber formation. Hence, the two cell populations comprising the posterior spiracle are distinct in terms of genetic control.

In this paper, we focus on the Drosophila melanogaster OAZ homologue, DmOAZ, the first invertebrate member of the OAZ family and the only member in the fruit fly. Although DmOAZ contains only 21 ZFs compared to 29$30 \mathrm{ZFs}$ in vertebrate $\mathrm{OAZ}$ members, $\mathrm{ZF}$ organization is partially conserved. We show that $d m O A Z$ is transcribed throughout life and is strongly expressed in the posterior spiracle of the embryo and larva. In the cascade of transcription factors involved in spiracular development, $d m O A Z$ appears to be a secondary target, downstream of $c t$ and ems. Hence, it may be implied in spiracular chamber specification. $d m O A Z^{93}$, a newly created loss-of-function mutant, is a larval lethal. $d m O A Z^{93}$ larvae exhibit a morphologically aberrant filzkörper, suggesting that larval lethality may be due to defective gas exchange.

\section{Materials and methods}

Fly strains

The following strains - all raised on standard cornmeal medium-were used: wild-type Canton-S, $A b d-B^{M 1}, c t^{d b 7}$, $e m s^{9 H 83}, \operatorname{Df}(2 \mathrm{~L}) \mathrm{enE}, g h^{B 32}, \mathrm{Df}(2) \mathrm{GR} 4, \operatorname{sal}^{I I B 57}, \mathrm{Df}(2 \mathrm{~L}) 5$, $\operatorname{trh}^{8}, \mathrm{Df}(2 \mathrm{R}) \mathrm{L} 48$, and $L^{02736}$. As marker constructs in which $\beta$-galactosidase expression was driven by specific enhancers, we used $c t$-D2.3, ems-1.2, and grh-D4 (Sarah Bray, unpublished). We also used ems-Gal4, UAS-GFP as reporter line (Merabet et al. 2005). All mutant alleles, deficiencies, and marker constructs were kindly provided by James Castelli-Gair Hombria (Universidad Pablo de Olavide, Sevilla), except $\operatorname{Df}(2 \mathrm{R}) \mathrm{L} 48$ and $L^{02736}$ (from Bloomington stock center). For complementation analysis, genotypes were balanced over $\mathrm{CyO}$. The $\mathrm{CyO}^{+}$phenotype was used to identify trans-heterozygous individuals resulting from the cross $(n>100$ adults scored in all cases). $d m O A Z$ mutants were generated by remobilizing the $\mathrm{P}[\mathrm{Gal} 4]$ element of the GH146 enhancer trap line (Stocker et al. 1997; Heimbeck et al. 2001).

Bioinformatics tools

For sequence alignment, we used LaLign, Clustal W, and Basic Local Alignment Search Tool (BLAST) at http://www. ch.embnet.org/. The BLAST tool offered by Flybase (http:// flybase.bio.indiana.edu/) was used to search conserved members in D. melanogaster and Prosite (http://www. expasy.org/prosite/) to determine the protein motifs.

\section{Reverse transcriptase-polymerase chain reaction}

Total RNA was isolated from about $20 \mu$ of embryos, from 20 third-instar larvae, and 16 adult flies respectively, by using the RNeasy Mini kit and the OneStep Reverse Transcriptase-Polymerase Chain Reaction (RT-PCR) Kit (Qiagen ${ }^{\circledR}$ ). Total RNA for homozygous $d m O A Z^{93}$ mutant was isolated from ten first-instar larvae. RT-PCR was performed on Biometra UNO II, using the primers rp49 as control and the following $d m O A Z$-specific primers: ATG ATG GCC CTA AAG ATG TTA TAT CG located in exon 1 and GGT GAT GAT GGA AGT GTG GC located in exon 2, which generate two bands corresponding to mRNA (292 bp) and to DNA (1,506 bp).

\section{Sample preparations}

Flies were allowed to lay eggs for $17 \mathrm{~h}$ at $22^{\circ} \mathrm{C}$ on small Petri dishes containing 2\% agar in $1: 1 \mathrm{dH}_{2} \mathrm{O}$ and grape juice. After embryo collection, the chorion was removed by treating with bleach. Embryos were then rinsed with $\mathrm{dH}_{2} \mathrm{O}$ and fixed for $20 \mathrm{~min}$ in 1:1 heptane and 3.7\% formaldehyde in phosphate-buffered saline (PBS). The aqueous phase was removed, and methanol was added to devitellinize the embryos. Embryos were stored in methanol at $-20^{\circ} \mathrm{C}$. Larval brains were dissected in PBS containing $0.2 \%$ Triton $\mathrm{X}-100$ (PBS-Tx 0.2\%). They were fixed on ice for $2 \mathrm{~h}$ in $4 \%$ paraformaldehyde in PBS-Tx $0.2 \%$. After three washes, tissues were dehydrated and then stored in $100 \%$ ethanol at $-20^{\circ} \mathrm{C}$. For adult brain preparation, the proboscis was removed, and the heads were fixed on ice for $2-3 \mathrm{~h}$. Then the brains were dissected in PBS, rinsed in PBS-Tx $0.2 \%$, and further treated as for larvae. For studying spiracular morphology, eggs were checked every hour to collect 0 - to 1-h-old first-instar larvae, which were embedded in Dako glycergel.

\section{Antibodies}

We used the following primary antibodies and concentrations: preabsorbed sheep anti-Digoxigenin-AP Fab fragments (1:2,000; Roche); preabsorbed sheep anti-Digoxigenin-POD Fab fragments (1:300; Roche); preabsorbed rabbit anti- $\beta$ gal (1:1,000; Cappel); mouse anti-Fasciclin II (1: 20; provided by C. Goodman, Berkeley); mouse anti-Cut 2B10 (1: 20; obtained from Developmental Study Hybridoma Bank, University of Iowa); and rabbit anti-Sal (1:25; provided by R. Schuh, Göttingen). The following secondary antibodies 
were used: biotinylated anti-rabbit (1:500; Vectastain ${ }^{\circledR}$ kit, Vector laboratories); biotinylated anti-mouse (1:500; Vectastain); goat anti-mouse Alexa 488 (1:200; Molecular Probes); and goat anti-rabbit Alexa 488 (1:200; Molecular Probes).

In situ hybridization and immunostaining

The RNA probe for $d m O A Z$ was generated from the RTPCR product obtained by using the primers ATG ATG GCC CTA AAG ATG TTA TAT CG located at the exon 1 start and GCT GCA GTT GAA CTC TGA GC located in exon 4 (fragment of 1,646 bp). This RT-PCR product was then subcloned in the pGEM-T easy vector (Promega). The vector was linearized by digesting with Nco I (antisense probes) and with Sal I (sense probes). The RNA probe for grh gene was generated from the RE30607 clone [from Berkeley Drosophila Genome Project (BDGP)], which contains the grh cDNA in the pFLC-1 vector. The linearization was obtained by digesting with Pfl MI. The trh RNA probe was obtained by digesting the RH17284 clone (provided by BDGP), which contains the cDNA of trh gene. It was linearized with Bbv CI. The DNAs were transcribed in vitro by using the Riboprobe Combination System T3/T7 (Promega) and a rNTPs mix containing Digoxigenin-11-UTP (Roche). Subsequently, DNAs were digested, and RNA probes were resuspended in $50 \%$ formamide, 50\% Tris-EDTA pH 7.5, and $0.1 \%$ Tween 20. The yield of in vitro transcription was estimated in a spot test (protocol according to Roche Nonradioactive In Situ Hybridization Manual). The RNA in situ procedure (Tautz and Pfeifle 1989) was adapted for alkaline phosphatase revelation (see: http://www.fruitfly.org/about/methods/ RNAinsitu.html). Anti-Digoxigenin-AP Fab fragments (Roche) were used to detect the probes, and Vectastain ${ }^{\circledR}$ Elite was applied for diaminobenzidine reaction. Specimens were mounted in $80 \%$ glycerol.

For fluorescent in situ hybridization, anti-DigoxigeninPOD Fab fragments (Roche) were used to detect probes. The signal was amplified via the tyramide signal amplification system, TSA ${ }^{\text {TM}}$-Plus Cyanine 3 System (Perkin-Elmer). The secondary antibody was incubated overnight at $4^{\circ} \mathrm{C}$.

Lethality counting, food ingestion

To determine lethality rates, 100 eggs were placed each in small Petri dishes containing grape juice agar. Eclosed larvae were counted, but only the homozygous larvae (or heterozygous $\mathrm{Df} / d m O A Z^{93}$ larvae) were collected in a new Petri dish for further observation. Development was followed until death; stages were distinguished by mouth hook morphology. Kaplan-Meier survival analysis was performed to test the differences in larval longevity between the control $d m O A Z^{43}$ and the genotypes $d m O A Z^{93}$, $d m O A Z^{93} / \mathrm{Df}$, and $\mathrm{Df}(2 \mathrm{R}) \mathrm{L} 48$. A total of 600 eggs for the balanced control $d m O A Z^{43}, 1,000$ for $d m O A Z^{93} / \mathrm{CyO}, 677$ for $d m O A Z^{93} / \operatorname{Df}(2 \mathrm{R}) \mathrm{L} 48$, and 400 for $\operatorname{Df}(2 \mathrm{R}) \mathrm{L} 48 / \mathrm{CyO}$ were used. Tests were run in Statistical Package for the Social Sciences 13.0. Food ingestion, tested by gut staining, was monitored by placing larvae on food containing $0.05 \%$ bromphenol blue.

\section{Results}

Sequence analysis of a putative D. melanogaster OAZ homologue

Among the 39 known families of ZF genes, CG17390 was identified as the gene encoding the putative homologue of the OAZ family in the fruit fly genome [referred to in this paper as DmOAZ (D. melanogaster OAZ homologue); (Knight and Shimeld 2001). By using Clustal W software (Thompson et al. 1994), we confirmed conservation of the entire sequence of DmOAZ with the human OAZ gene. We obtained $21 \%$ identity and $50 \%$ similarity (Fig. 1a), in spite of a reduced number of $21 \mathrm{ZF}$ domains compared to the 29-30 ZFs present in vertebrates (Tsai and Reed 1997, 1998; Hata et al. 2000; Warming et al. 2003, 2004). We also confirmed that DmOAZ is the unique OAZ member in the fruit fly.

Hata et al. (2000) proposed a model in which the ZF motifs of the OAZ protein are organized in clusters according to their binding ability. They identified four sets of ZFs: (1) two DNA-binding domains (cluster A: ZFs 28 implied in Olf/EBF pathway; cluster B: ZFs $9-13$ in BMP-Smad pathway), (2) Smad-binding domain (cluster C: ZFs 14-19), (3) a cluster D with unknown function (ZFs 20-27), and (4) Olf/EBF-binding domain (cluster E; ZFs 28-30). The function of the ZF 1 was not yet characterized. By summarizing the different studies on OAZ family members, we noted that this organization was conserved (Tsai and Reed 1997, 1998; Hata et al. 2000; Shim et al. 2002; $\mathrm{Ku}$ et al. 2003; Warming et al. 2003, 2004). To structurally analyze the DmOAZ protein, we determined the arrangement of the $21 \mathrm{ZFs}$ in four clusters by using Simple Modular Architecture Research Tool software (http://smart.embl-heidelberg.de; Schultz et al. 1998; Letunic et al. 2004), and we aligned each DmOAZ cluster on the entire sequence of the orthologues. Although clusters $\mathrm{A}, \mathrm{C}$ and $\mathrm{D}$ aligned correctly with their vertebrate counterparts (Fig. 1a, Electronic Supplementary Fig. 1), no significant alignments were obtained for clusters $\mathrm{B}$ and $\mathrm{E}$. When testing the sequence of each ZF motif individually against the entire sequence of the vertebrate homologues, we confirmed that each individual ZF motif belongs indeed to the clusters indicated above, except ZFs 8, 14, 15, 17, 


\section{a}

\section{ZFs 1-4 (cluster A)}

hOA2 45 RNSVTSQEEANEDJEDMEDESIYTCDHCQQDFESLADLTDHRAHRCPGDGDDOPQLSWVA ROA2 1 ZF1-4 APTAGQEDHPTEGKINGGADGEDLPKPKRLPHFHHHHHHHYHQQALKIANKLRKINKE

hOAZ 105 SSPSSKDVASPTQMIGDGCDLGLGEEEGGTGLPYFCQFCDKSFIRLSYLKRHEQTHSDKL ROAZ I -----MIGDGCDLGLGEEEGGTGL PYF CQECDKSFIRLSYLKRHEQIHSDKL. EBFA2 113 SSPSSKDVASPTQMICDGCDLGLGEEECCTGLPYPCQFCDKSFIRLSYLKRHEQIHSDKL. 2F1-4 AKNGATAGGGATGAASKFDKLTGEGIKSRGDGSYCCQECEKTFPRLGYLKHHVQSHAEHL

hOA2 165 PEKCTYCSRLFKHKRSRDRHIKLHTGJKKYHCHECEANFSRSDHLKIHLKFHSSSKPFKC $\begin{array}{lrl}\text { ROAZ } & 48 & \text { PFKCTFCSRLFKHKRSRDRHIKLHFGDKKYHCHECEAAFSRRDHLKIHLKTHSSSKPFKC } \\ \text { EBEAZ } & 173 & \text { PFKCTFCSRLFKHKRSRDRHIKLHFGDKKYHCHECEAAFSRSDHLKIHLKCHSSSKPFKC }\end{array}$ $\begin{array}{lll}\text { EBEAZ } & 173 & \text { PFKCTFCSRLFKHKRSRDRHIKLHFGDKKYHCHECEAAFSRSDHLKIHLKTHSSSKPFKC } \\ \text { 2F1-4 } & \text { PFKCEYCSKLFKHKRSRDRHKKLHTNERNYKCPHCEAAFSRSDHLKIHMKTHDIQKPFQC }\end{array}$

hOAZ 225 FVCKRGESSTSSLOSHMQAHKKNKEHLAKSEKEAKKDDFMCDYCEDTFSQTEELEKHVLT ROAZ 108 VVCKRGESSTSS LOSHMQAHKKNKEHLAKSEKEAKKDDFMCDYCEDTFSQTEELEKHVLT EBFAZ 233 SVCKRGFSSTSSLQSHMQAHKKNKEHLAKSEKEAKKDDFMCDYCEDTESQTEELEKHVLT ZF1-4 EMCNRGYNTAAALTSHMQKHKKNAAI LAMGGNPNALN--

\section{ZFs 7-13 (cluster C)}

hOAZ 574 FGSILKLTKHIKENHKNI PLAHSKKSKAEQS PVSSDVEVSSPKRQRLSASANSISNGEY ROAZ 476 FGSILKLTKHITENHKNI PLAIISKKSKAEQSPVSSDVEVSSPKRQRLSGSANSIINGEY EBFAZ 582 FGSILKLTKHIKENHKNI PLAHSKKSKAEQS PVSSDVEVSSPKRQRLSGSANSISNGEYP

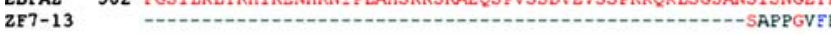

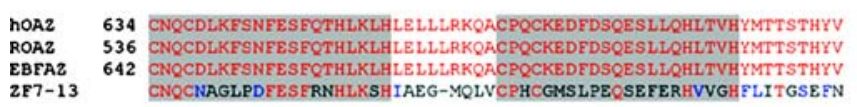

hOA2 694 CES-CDKQESSVDDLQKHLLDNHTFVYYCTLCQEVEDSKVSIOVHLAVKHISNEKKMYRC

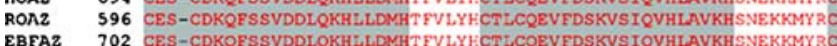

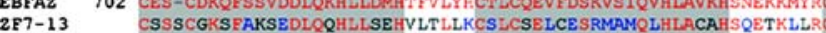

hOA2 753 TACNWDERKEADLQVHVKHSHLGN------PAKAHKCIFCGETESTEVELOCHI ROAZ 6S5 TACNWDERKEADLQVHVKHSHLGN---1 PAKAHKCIFCGETFSTEVELQCHIT 2F7-13 SACLELERSDAEFHVHVKTRHOLGGHPTLGATSSAPTNPLOCMFCRAVCSSELEMHFHIA

hOAZ $\mathbf{8 0 2}$ THSKKYNCKFCSKAEHAI ILLEKHLREKHCVFDAATENGTANGV PPMATKKAEPAD LQGM ROAZ 704 THSKKYNCRFCSKAFHAVLLLEKHLREKHCVFJPAAENGTANGVPPTSTKKAE PADLQG

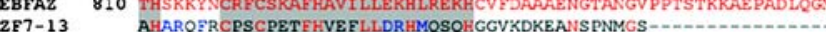
ZFs 14-18 (cluster D)

hOA2 814 KAFHAIILLEKHLREKHCVFCAATENGTANGVPPMATKKAEPADLQGMLLKNPEAPUSHE ROA2 716 KAFHAVLLLEKHLREKHCVEDPAAENGTANGVPPTSTKKAEPAD LQMLLLNPEAPNSHE $\begin{array}{lll}\text { EBFA2 } & \mathbf{8 2 2} \text { KAFHAVILLEKHLREKHCVEDAAAENGTANGVPFTSTKKAEPADEQGVLLKNPEAPNSHE } \\ \text { 2F14-18 } & & \end{array}$ hOA2 874 ASEDDVDASE PMYGCDICG-AAYTMEVLLQNHRLRDHNIRPGEDDGSRKKAEFIKGSHKC
ROAZ 776 ASEDDVDASEPMYGDICG-AAYTMEVLLQNHRLRDHNIRPGEDDGSKKAEFIKGSHKC $\begin{array}{lll}\text { ROAZ } & \mathbf{7 7 6} \text { ASEDDVDASE PMYGCDICG-AAYTMEVLLONHRL.RDHVIRPGEDDGSRKKAEFIKGSHKC } \\ \text { EBYAZ } & \mathbf{8 8 2} \text { ASEDDVDASE.PMYGCDICG-AAYTMEVVLLONHRL.RDHNIRPGEDDGSRKKAEFIKGSHKC }\end{array}$

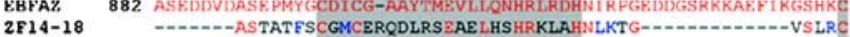

hOA2 933 NVCSRTFFSENGLREHLOTHRGPAKHYYCPICGEREPSLLTLTEHKVTHSKSLDTGTCRI ROAZ 835 NVCSRTFFSENGLREHLQTHRGPAKHYNCPICGERFPSLLTLTEHKVTHSKSLDTGTCR EBFA2 941 NVCSRTFESENGLREHLQTHRGPAKHYCPICGEREPSLLTLTEHKVTHSKSLDTGTCRI

hOA2 993 CKMPLOSEEEFIEHCOMHPDLRNSLTGFRCVVCMOTVTSTLELKIHGTFHMOKLAGSSAA ROAZ 893 CKMPTOSEEEFIEHCOMHPDIRNSLTGERCVVCMOTVTSTLELKIHGTFHMQKLAGSSAA

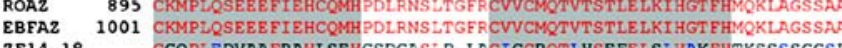
2F14-18 CGQPLEDVAAFRAHLSEHGSDGASLP-LACICCRQTLHSEFELSLHAKFHTKSSSSGGSL

Fig. 1 Protein sequence and $\mathrm{ZF}$ organization of DmOAZ and sequence alignment with vertebrate members of the $\mathrm{OAZ}$ protein family. a Alignment of the ZF clusters of DmOAZ (D. melanogaster) with the homologous sequences from human (hOAZ; accession number AAF28354), rat (ROAZ; accession number AAB58646), and mouse (EBFAZ; accession number AAG17053), using Clustal W. Significant alignment is obtained for clusters $A, C$ and $D$ (ZFs shown in grey, conserved residues in red). b Sequence alignment reveals considerable conservation of ZF cluster organization between vertebrate and Drosophila OAZ members. All ZFs align correctly except ZFs $8,14,15,17$, and 20 of DmOAZ (indicated by a green cross).
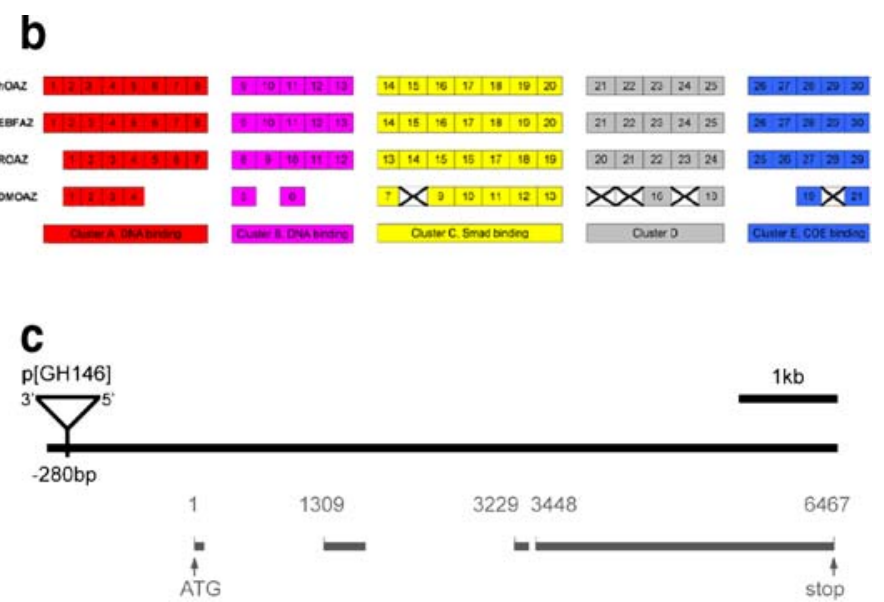

\section{d}

MMALKMLYRGPSSRLENLIEKIQATKEITNNDMYSTHTSSSYSPSISDGTMTPNSHHLIGAP TAAGQEDHPTEGKINGGADGEDLPKPKRLPHFHHHHHHHYHHQQALKIANKLRKINKEAK MGATAGGGATGAASKFDKLTGEGIKSRGDGSYQCQFCEKTFPRLGYLKHHVQ $S H A E H L P \bar{F}$

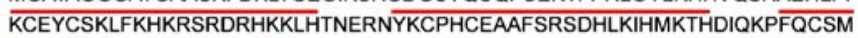
CNRGYNTAAALTSHMQKHKKNAAILAAGGNPNALNYSPRSTGSASASVSSNGSLQKRRYA LALASDSSPSRMDFPKRSRSNHVGGTTTTATPTPLLRCSYCPKVTEFSSLEQLNAHLQSVH EQPQTQGVKTPVQEGEGFQLSCEYCTMKFGNIAGLFQHMRSTHMDRLSSPNSYYEHFNR LATAGTFSPRLALDLPKIKPDLGSPERESRPAEDDLPTDLSNNKRRPLTPNPQAQTPLAPPS APPGVFFCNQCNAGLPDFESFRNHLKSHIAEGMQLVCPHCGMSLPEQSEFERHWVGHFLI TGSEFNCSSSCGKSFAKSEDLQQHLLSEHVLTLLKCSLCSELCESRMAMQLHLACAHSQE TKLLRCSACLELFRSDAEFHVHVKTRHQLGGHPTLGATSSAPTNPLQCMFCRAVCSSELE MHFHLAAHARQFRCPSCPETFHVEFLLDRHMQSQHGGVKDKEANSPNMGSLYVNALLPP LAAAAAAAAATNNNSSIIDYNVAFKGLFGGASGGAGSGGGGAQSGGAPPSANKFYSPLQV DTNALKAQTSPHPALMYGLSQRYLMEMYAAKSTSPSGNEGVGNSQPPAPQATAPPPPPNA STATFSCGMCERQDLRSEAELHSHRKLAHNLKTGVSLRCAYCAGNFKSRAELEQHMKSCH NSTGKHKCLICDEVFPSPAILAEHKLQHSKVGQSGKCSHCGQPLEDVAAFRAHLSEHGSD GASLPLACICCRQTLHSEFELSLHAKFHTKSSSSGGSLQEPVCALCLEPLPDATEGPAKLCD KCCRKHNLNGKRGKHSEPATSLPAPPSAFVENRCNLCKMILPHAQKLQEHLVEHTFAGTEQ RGFNCYICSAVFTAPGGLLNHMGEHGAHSRPYDCNLCPEKFFFRAELEHHQRGHELRPQA

c Schematic representation of the dmoaz locus. The genomic map is shown on top, in black. The P[GawB] element of the GH146-Gal4 line is inserted $280 \mathrm{bp}$ upstream of the $A T G$, in the orientation $3^{\prime}-5^{\prime}$. $A T G$ represents the initiation codon of the open reading frame. Exon/ intron organization of the transcript is shown below; exons are marked by grey lines, and their positions are indicated as relative distance from ATG (located at 9'973'599 in Flybase and 82'062 in the National Center for Biotechnology Information). Arrows indicate start and stop codons. d Deduced protein sequence of DmOAZ. The 21 zinc fingers are represented by a colored bar. The color corresponds to the different ZF clusters 
and 20, which did not align correctly (Fig. 1b). In conclusion, we obtained correspondence of most of the $\mathrm{ZF}$ clusters between DmOAZ and its vertebrate counterparts. However, functional experiments are required to confirm this proposed organization of the DmOAZ ZF domains.

Determination of mRNA and DmOAZ encoding sequences in the fruit fly

The CG17390 sequence (Adams et al. 2000) is located on the right arm of chromosome II at 51A3-4. It encodes a transcription factor characterized by $21 \mathrm{ZF}$ domains. An incomplete expressed sequence tag (EST) AT08673 of 3,100 base pairs (bp) corresponding to the $3^{\prime}$ end of CG17390 was available from the "EST and BDGP project cDNAs" database. By performing RT-PCR on wild-type flies, we cloned a 1,653-bp fragment corresponding to the $5^{\prime}$ side of $d m O A Z$, consisting of three exons and the first 855 bp of the EST AT08673.

In an extensive RT-PCR analysis of the transcript corresponding to CG17390, we found that CG17390 is coding for a single 3,687-bp transcript (Fig. 1c) and that the intron/exon structure of $d m O A Z$ is slightly different from the theoretical structure reported in Flybase. Indeed, we determined an organization consisting of three introns and four exons (exon 3 mentioned in Flybase is missing) in the wild type. Accordingly, we deduced an open reading frame of 1,229 amino acids (Fig. 1d). RT-PCR performed in the wild type demonstrated that $d m O A Z$ is transcribed in embryos, first- and third-instar larvae, late pupae, and adults (Fig. 2). The 292-bp bands which were present at each developmental stage represent the $d m O A Z$ mRNA. No

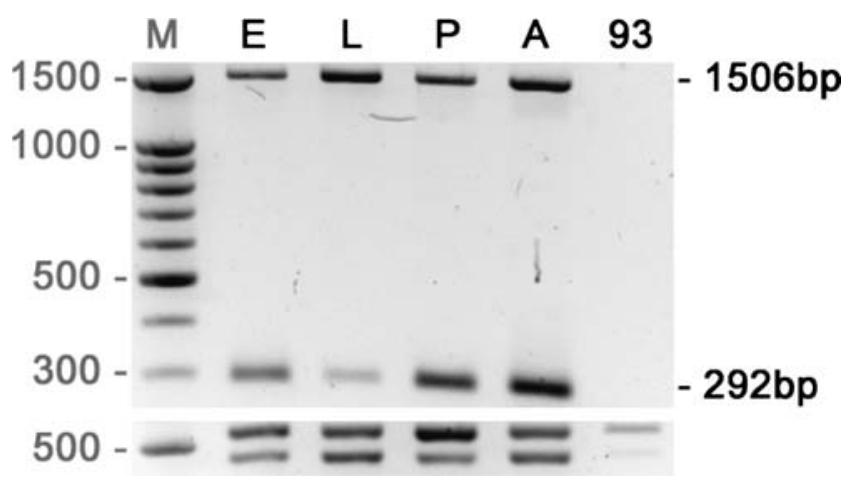

Fig. 2 Transcription of $d m O A Z$ in the wild-type Canton $\mathrm{S}$ and in the mutant $d m O A Z^{93}$ of $D$. melanogaster. RT-PCR with a primer set specific for $d m O A Z$ transcript shows the presence of the $d m O A Z$ transcript in embryos $(E)$, larvae $(L)$, pupae $(P)$, and adults $(A)$ of the wild type but not in homozygous $d m O A Z^{93}$ first-instar larvae (93). We used primers located in exon 1 and 2, respectively. Therefore, the 1,506-bp and 292-bp bands represent, respectively, the DNA and mRNA. As a control, we performed RT-PCR with the primer set specific for rp49 transcript to determine the presence of mRNA and DNA. Total RNA was efficiently isolated for each sample. $M$ marker transcriptional difference was observed between males and females at larval and adult stages.

DmOAZ is strongly expressed in posterior spiracles of the embryo

We then focused on embryonic expression of CG17390. We confirmed previous results (cf. BDGP gene expression report; http://www.fruitfly.org/cgi-bin/ex/insitu.pl) also by performing in situ hybridization, and we found additional specific staining in the peripheral nervous system (PNS) from stage 14 (Campos-Ortega and Hartenstein 1997) onward. However, strongest $d m O A Z$ expression was observed in the posterior spiracles. DmOAZ staining became visible in their anlage at stage 11 and persisted throughout embryogenesis (Fig. 3a-c). Expression was also detected in both anterior and posterior spiracles of third-instar larvae (Fig. 3d), as well as in thoracic and abdominal spiracles of adults (Fig. 3e), suggesting that $d m O A Z$ may be involved in spiracle development and function. In the adult, we found additional staining in olfactory projection neurons, which link the primary and secondary olfactory centers.

To study the role of $d m O A Z$ in posterior spiracle development, we determined in which of its two cell populations $d m O A Z$ is expressed. When using an antibody against Spalt (Kuhnlein et al. 1994), which stains exclusively the stigmatophore-forming cells, we did not obtain any co-localization, ruling out a role of $d m O A Z$ in this part of the spiracle. In contrast, when we used the reporter lines ems-1.2-lacZ (Jones and McGinnis 1993) and grh-D4-lacZ (Sarah Bray, unpublished) that label different groups of cells in the spiracular chamber, about two thirds of the $d m O A Z$-positive cells were co-labeled by ems-1.2-lacZ (Fig. 3f) and about one third of them by grh-D4-lacZ (Fig. 3g). These lines allowed to show that, during spiracular development, the invagination of the spiracular chamber is accompanied by drastic cell shape changes, such as an elongation of the cells labeled by grh-D4-lacZ (Hu and Castelli-Gair 1999). Applying an anti-Cut antibody in combination with $d m O A Z$ in situ hybridization yielded co-labeling in slightly less than half of the $d m O A Z$-positive cells (Fig. 3h). Correspondingly, DmOAZ is co-expressed in a partially overlapping pattern with $\mathrm{Ct}$ protein and with ems and grh reporter lines.

$d m O A Z$ acts downstream of ems and cut in posterior spiracle development

Previous works have shown that $A b d-B$-loss-of-function alleles of which lack the posterior spiracles - initiates the developmental cascade of this organ (Lamka et al. 1992) and that two categories of genes are the targets of $A b d-B$ (Hu and Castelli-Gair 1999; Hombria and Lovegrove 2003; 
Fig. 3 Expression pattern of $d m O A Z$ mRNA. (a-e) In situ hybridization with a $d m O A Z$ specific RNA probe and alkaline phosphatase staining in the Canton $\mathrm{S}$ wild type. Lateral view (a $1-\mathbf{c} 1)$ and dorsal view (a 2-c 2) of embryos showing the presence of $d m O A Z$ mRNA in spiracles $(S P)$. a Stage 11, b stage 13 , c stage 16 . Additional staining is revealed in the ventral PNS from stage 13. d In third-instar larvae, staining was observed in anterior (d 1$)$ and posterior spiracles (d 2); $\mathbf{e}$ in adults, label was present in thoracic (e 1 ) and abdominal spiracles (e 2). f, g In stage 16 posterior spiracles, $d m O A Z$ RNA (red) partially co-localizes with $\beta$ gal expression (green) of ems- and grh-reporter lines (indicated on panels). $\mathbf{h}$, i Cut protein and DmOAZ mRNA partially co-localize in posterior spiracles (h l) and the cutexpressing cells are maintained in $d m O A Z^{93}$ (compare $\mathbf{h} 2$ and $\mathbf{i}$ )
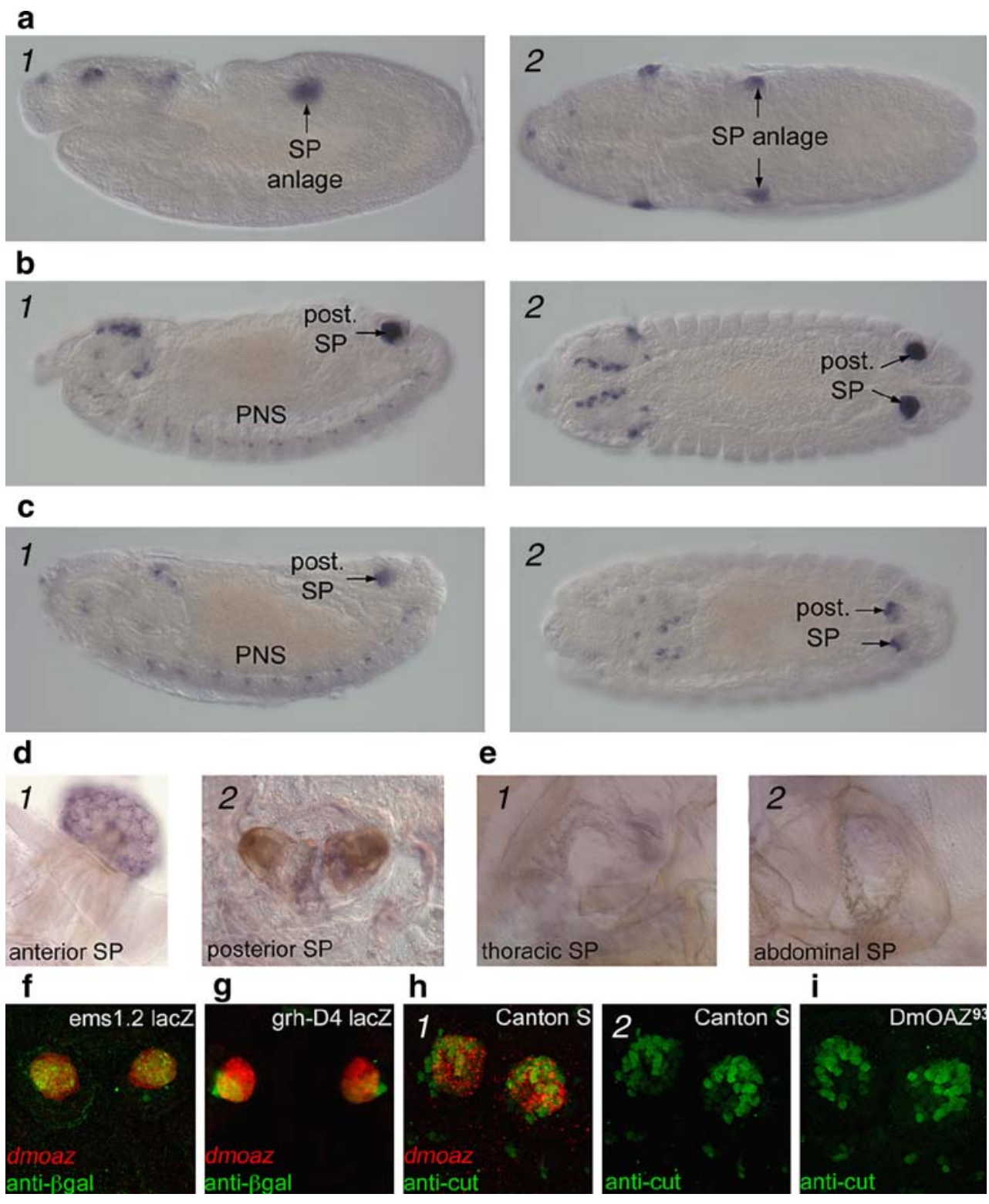

e

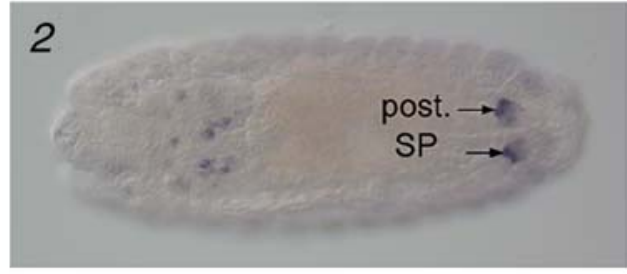

e
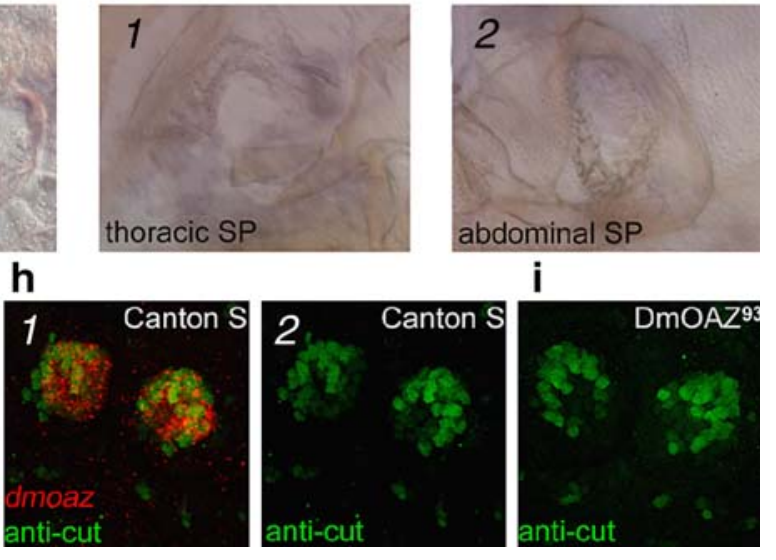

i

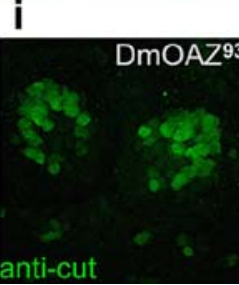

Merabet et al. 2005). The sal gene (Kuhnlein et al. 1994) and its targets en (Patel et al. 1989) and grn (Brown and Castelli-Gair Hombria 2000) are implicated in stigmatophore development, whereas ct (Blochlinger et al. 1990), ems (Walldorf and Gehring 1992; Dalton et al. 1989), klu (Klein and Campos-Ortega 1997), and $n u b$ (Ng et al. 1995), as well as the two genes trh (Isaac and Andrew 1996) and grh (Bray and Kafatos 1991) - both downstream of $c t$ and ems - are involved in spiracular chamber formation.

To localize $d m O A Z$ in this cascade, we performed $d m O A Z$ in situ hybridization on mutant embryos. As DmOAZ is specifically expressed in the cell population forming the spiracular chamber, we expected its expression to be affected specifically in mutants for genes involved in chamber development. Indeed, $d m O A Z$ expression in the posterior spiracle was abolished in $A b d-B^{M 1}$ and $e m s^{9 H 83}$ mutants (Fig. 4a,b). This suggests that $d m O A Z$ is not an early target of $A b d-B$ but rather a secondary target acting downstream of ems. In addition, the number of $d m O A Z$ expressing cells in the posterior spiracle was also reduced by less than a half in the $c t^{d b 7}$ mutant (Fig. 4c). In contrast, the number of cells expressing Cut was not reduced in homozygous $d m O A Z^{93}$ mutant embryos as compared to CS embryos, confirming that $d m O A Z$ does not act upstream of cut (Fig. 3h 2,i). This result suggests that $d m O A Z$ expression may be regulated both by ems and ct. However, cut seems to control $d m O A Z$ expression only in a subset of $d m O A Z$-expressing cells. With other spiracular chamber mutant lines, $g r h^{B 32}, \operatorname{trh}^{8}$, and Df(2)GR4 [deficient for $p d m-1(n u b)$ and the structurally related gene $p d m-2]$, we obtained normal $d m O A Z$ expression (Fig. 4d,e). We also studied the grh and trh expression patterns in the $d m O A Z^{93}$ 
Fig. $4 d m O A Z$ in situ hybridization at embryonic stage 16 in the different mutants implied in the development of the posterior spiracle (black arrows). a, b $d m O A Z$-specific staining is abolished in the posterior spiracles of Abdominal-B (a) and empty spiracles (b) mutants. c In $c u t$, the number of $d m O A Z$ expressing cells (white arrowhead) is reduced (compare $\mathbf{c} 2$ with $\mathbf{c} 3$ ). $\mathbf{d}-\mathbf{f} d m O A Z$-specific staining is maintained at wildtype levels in grainy head (d), trachealess (e) and spalt (f 1$)$. In spalt and spalt-r mutants (f 2), dmOAZ-expressing cells were observed to be split into two groups (white arrow) in 15\% of the homozygous mutant embryos. g-h Both grh-(g) and trh-specific staining (h) are maintained at wild-type levels in $d m O A Z^{93}$ mutant embryos a

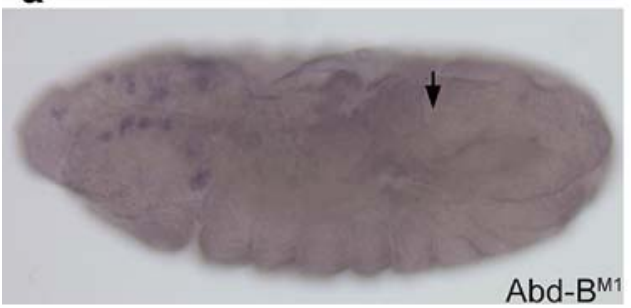

\section{C}

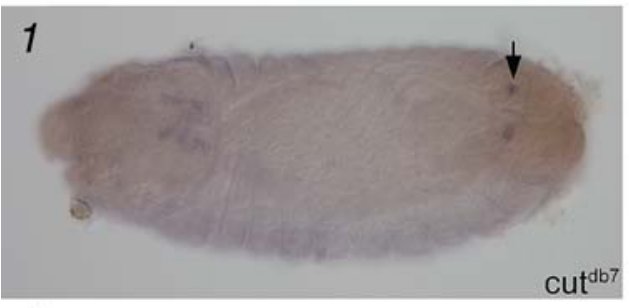

d

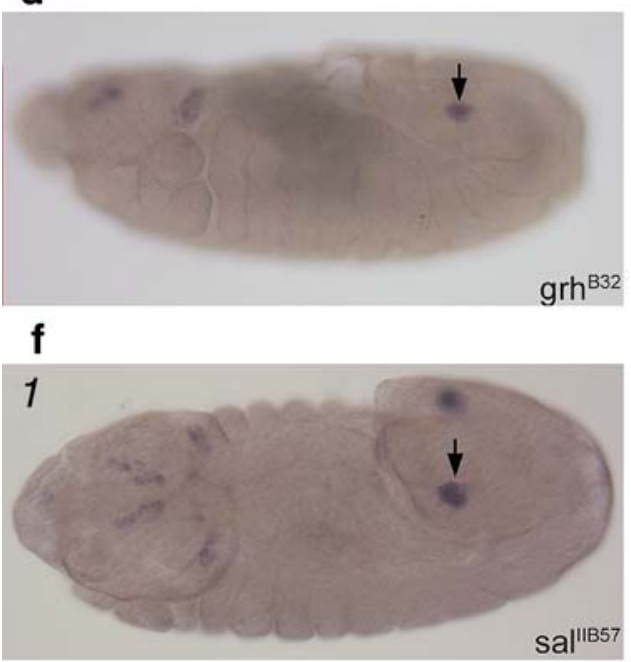

g

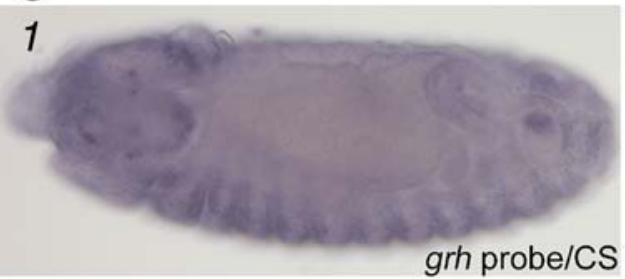

h

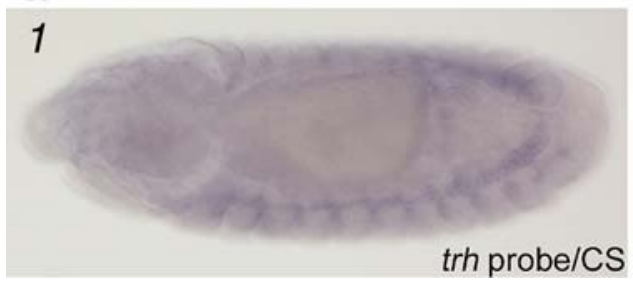

b
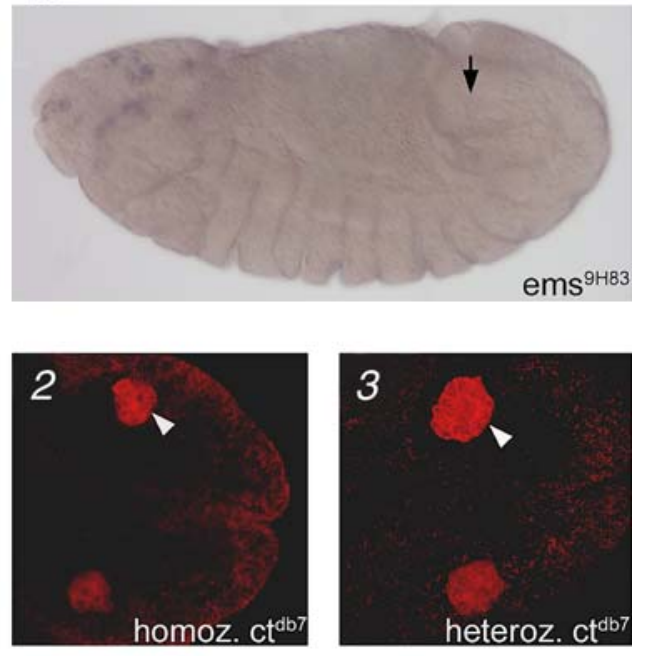

e
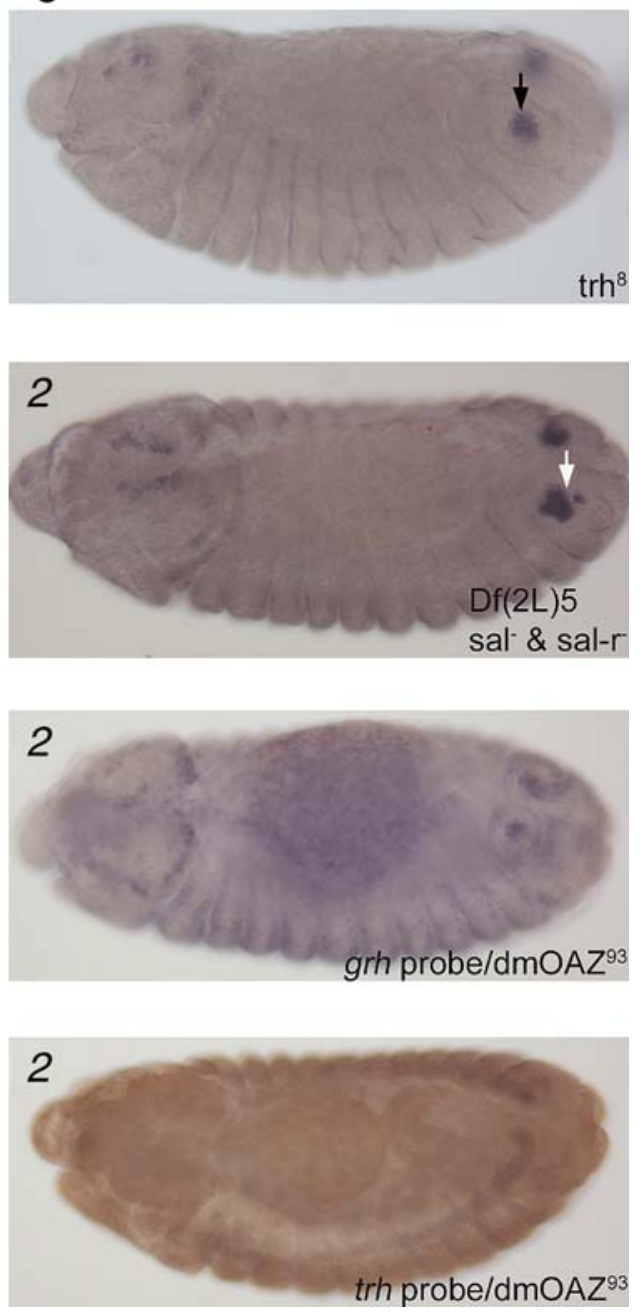

mutant. We performed in situ hybridization with RNA probes of the grh and trh genes, respectively, and we observed no difference in mRNA presence of these two genes in homozygous $d m O A Z^{93}$ mutant embryos as compared to $\mathrm{CS}$ embryos, confirming that $d m O A Z$ does not act upstream of grh and trh genes (Fig. 4g,h).

Not surprisingly, DmOAZ expression was not modified in mutants affecting stigmatophore development, i.e., 
sal ${ }^{I I B 57}$ and $\operatorname{Df}(2 \mathrm{~L})$ enE (deficient for en and invected; Fig. $4 \mathrm{f} 1$ ). Taken together, these data suggest that the $d m O A Z$ gene is specifically involved in spiracular chamber development but not in stigmatophore development. Nevertheless, $d m O A Z$-labelled cells showed a certain disorganization in the $\operatorname{Df}(2 \mathrm{~L}) 5$ line (deficient for sal and sal-r) in one sixth of the homozygous mutants (Fig. 4f 2). Specifically, some cells were separated from the main group of $d m O A Z$-expressing cells. This particular pattern could be a consequence of a general disorganization of the posterior spiracle due to the absence of both sal and sal-r.

Generation of a $d m O A Z$ loss-of-function mutation

To study the function of DmOAZ in spiracle development, we generated $d m O A Z$ mutants. The $\mathrm{P}[\mathrm{GawB}]$ transposable element of the GH146-Gal4 enhancer trap line (Stocker et al. 1997; Heimbeck et al. 2001) is inserted close to the dmOAZ map position at 51A3-4. We cloned and sequenced the P element-flanking sequences by inverse PCR (Dalby et al. 1995). Blast analysis revealed that $\mathrm{P}[\mathrm{GH} 146]$ is ideally inserted 280 bp upstream of the $d m O A Z$ start codon (at position 9'973'599 on 2R). Hence, we created $d m O A Z$ mutants by remobilizing the P[GH146] transposable element. From the 180 isolated lines, we recovered 20 homozygous lethal lines and characterized one of them, $d m O A Z^{93}$, in more detail.

We first determined the developmental stage at which lethality occurred in $d m O A Z^{93}$ (Fig. 5). To qualify and quantify this phenotype, we used the precise excision line $d m O A Z^{43}$ as a control. $d m O A Z^{43}$ individuals were observed to reach the third larval instar or subsequent stages. To determine if lethality was due to the loss-of-function of the $d m O A Z$ gene, we studied heterozygous $\operatorname{Df}(2 \mathrm{R}) \mathrm{L} 48 /$ $d m O A Z^{93}$ individuals, $\mathrm{Df}(2 \mathrm{R}) \mathrm{L} 48$ covering the $d m O A Z$ region (Jürgens 1985; Schüpbach and Wieschaus 1991; Chang et al. 1995; Dickson et al. 1995). The hatching column in Fig. 5 refers to a mixed population of homozygous and heterozygous embryos. We noted weak lethality due to the manipulation (Fig. 5). For the larval stages, only the fraction of non-balanced individuals from the eclosed larvae was considered $\left(\mathrm{dmOAZ} Z^{43}, \mathrm{dmOAZ}^{93}\right.$, $d m O A Z^{93} / \mathrm{Df}(2 \mathrm{R}) \mathrm{L} 48$, and $\operatorname{Df}(2 \mathrm{R}) \mathrm{L} 48$, respectively): therefore, the maximal theoretical value that we can obtain is about $33 \%$, as the homozygous $\mathrm{CyO}$ individuals are lateembryonic or early-larval lethals. The value of about $25 \%$ for the homozygous $d m O A Z^{43}$ larvae is, in fact, a good control. Of course, the weak lethality due to the manipulation is also present in larval stages. However, KaplanMeier survival analysis showed that the lethality rate of homozygous $d m O A Z^{93}$ individuals was not significantly different from $d m O A Z^{93} / \mathrm{Df}(2 \mathrm{R}) \mathrm{L} 48$, whereas $d m O A Z^{43}$ was significantly different from all others (Fig. 5; p«0.01).

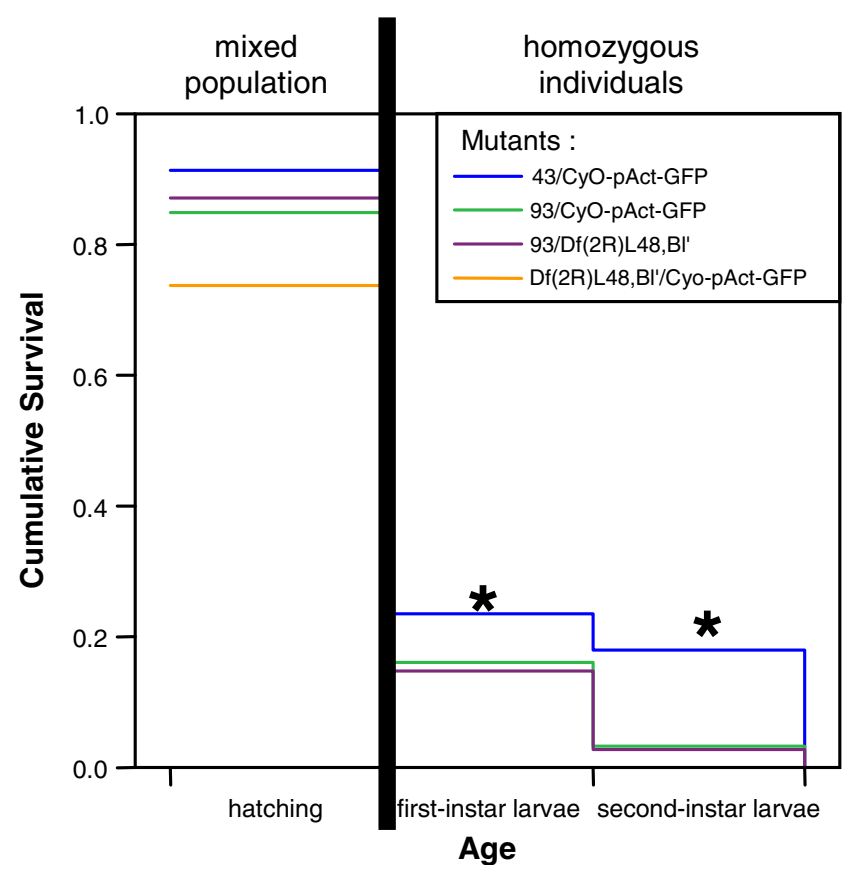

Fig. 5 Survival rates of $d m O A Z$ mutant larvae. The survival rate of $d m O A Z^{93}$ is not significantly different from $d m O A Z^{93} / \mathrm{Df}(2 \mathrm{R}) \mathrm{L} 48$, while the survival rate of the $d m O A Z^{43}$ control is significantly different from the other genotypes (asterisk $\mathrm{p} \ll 0.01$; Kaplan-Meier survival analysis). The hatching column refers to a mixed population of homozygous and heterozygous individuals, while for first- and second-instar larvae, only the non-balanced individuals were considered $\left(d m O A Z^{43}, d m O A Z^{93}, d m O A Z^{93} / \operatorname{Df}(2 \mathrm{R}) \mathrm{L} 48\right.$, and $\operatorname{Df}(2 \mathrm{R}) \mathrm{L} 48$, respectively)

Hence, we conclude that $d m O A Z^{93}$ is a genetically null allele. In agreement with this interpretation, both in situ hybridization and RT-PCR experiments did not reveal any $d m O A Z$ mRNA in homozygous $d m O A Z^{93}$ embryos or firstinstar larvae (Fig. 2).

To verify whether lethality is due to a mutation in the $d m O A Z$ locus rather than in adjacent loci, we performed complementation tests. On the one hand, we used $\operatorname{Df}(2 \mathrm{R})$ L48, which covers the $5^{\prime}$ and $3^{\prime}$ regions surrounding the $d m O A Z$ locus. On the other hand, we studied a homozygous lethal recessive allele of Lobe, $L^{02736}$, mapping to the $3^{\prime}$ side of $d m O A Z$. A similar experiment for the $5^{\prime}$ side was not performed because PCR demonstrated that this region is intact in $d m O A Z^{93}$ (data not shown). From this experiment, we conclude that larval lethality is indeed due to $d m O A Z$ loss-of-function.

The $d m O A Z$ loss-of-function mutation impairs spiracle morphogenesis

To study whether larval lethality is due to a feeding defect, vital dye was added to the food. Homozygous $d m O A Z^{93}$ firstand second- instar larvae showed characteristic gut staining, similar to balanced $d m O A Z^{93}$ larvae (data not shown). Hence, a feeding defect as a cause of lethality can be excluded. 
Given the strong expression of $d m O A Z$ in posterior spiracles, we studied the morphology of this structure in newly eclosed first-instar larvae (0 to 1-h-old). Although heterozygous larvae $d m O A Z^{93}$ (Fig. 6b) showed a filzkörper structure comparable to the wild type (Fig. 6a), the filzkörper was obviously thinner and more elongated both in
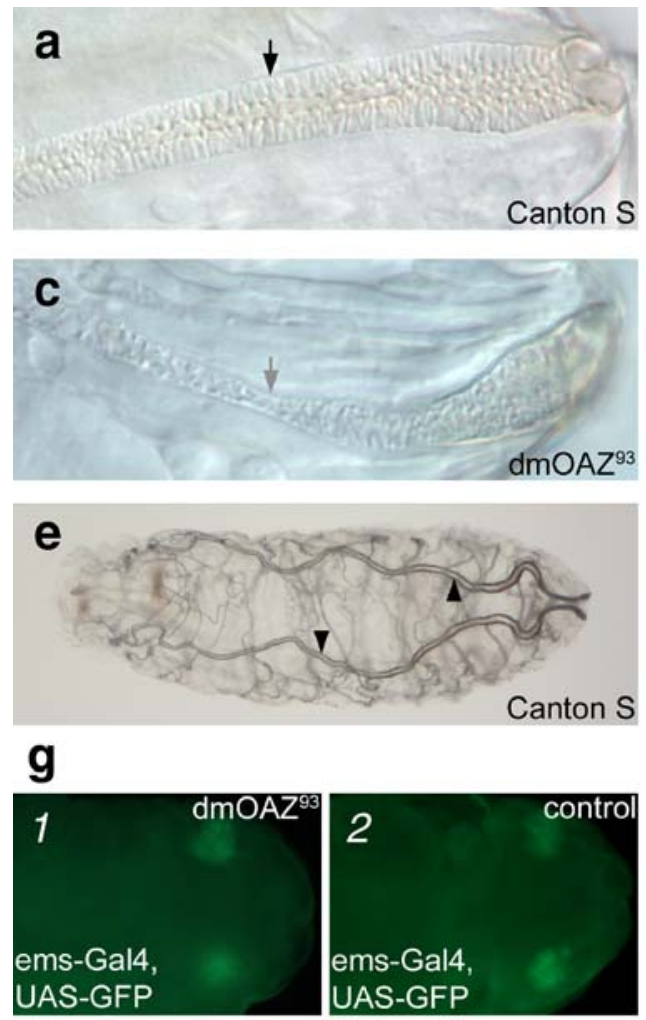

i

\begin{tabular}{l|c} 
mutants & $\begin{array}{c}\text { marker dmOAZ } \\
\text { (in situ hybridization) }\end{array}$ \\
\hline Abd-B & - \\
ems $^{9 H 83}$ & - \\
cut $^{\mathrm{db7}}$ & $+/-$ \\
grh $^{\text {B32 }}$ & + \\
trh $^{8}$ & + \\
sal $^{11857}$ & +
\end{tabular}

Fig. 6 a-h Structural and functional mutant phenotypes in the posterior spiracle and tracheae, $\mathbf{i}$ summary of $d m O A Z$ expression in different mutant background, and (j) proposed model of genetic control of posterior spiracle development. a-f Mutant effects in posterior spiracles and tracheal branches of 0 - to 1-hr-old $d m O A Z^{93}$ larvae (Nomarski optics). While the filzkörper shows constant thickness (black arrows) in the wild type (a) and in heterozygous $d m O A Z^{93}$ larvae (b), it is extended and thinner (grey arrows) in homozygous $\mathrm{dmOAZ}^{93}$ larvae (c) and in heterozygous $\mathrm{dmOAZ}^{93} / \mathrm{Df}$ (2R)L48 larvae (d). e, f Air fills completely the main tracheal branch in the wild type (e, black arrowheads), but not in the $\mathrm{dmOAZ}^{93}$ mutant (f, white arrowheads). $\mathbf{g}-\mathbf{h}$ In two subsets of spiracular chamber cells, labeled by the reporter lines ems-Gal4, UAS-GFP (stage 12, g) and homozygous $d m O A Z^{93}$ (Fig. 6c) and in $\operatorname{Df}(2 \mathrm{R}) \mathrm{L} 48 /$ $d m O A Z^{93}$ larvae (Fig. 6d). In contrast, the spiracular hairs looked normal in these two mutant conditions. These results further support an implication of the $d m O A Z$ gene in the morphogenesis of the posterior spiracle.
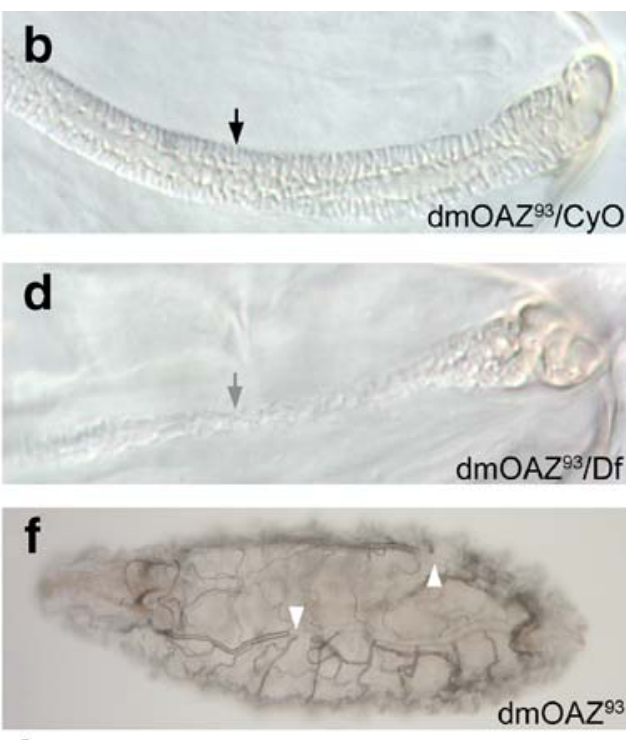

h
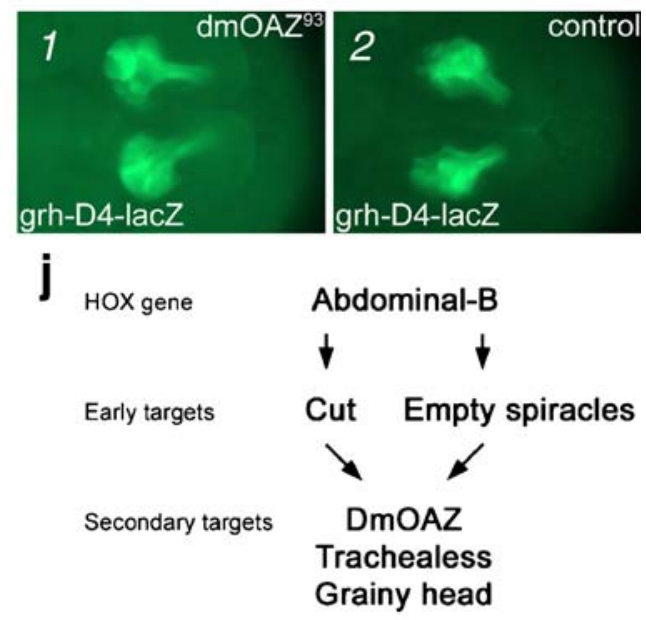

grh-D4-lacZ (stage 14, h), respectively, no changes in shape and position were observed when comparing their patterns in the $d m O A Z^{93}$ mutant background $(\mathbf{g} 1, \mathbf{h} 1)$ and the control background $(\mathbf{g} 2, \mathbf{h} 2)$. i Summary of $d m O A Z$ expression in various mutants $(+$, normal expression; +/-, reduced expression; - , no expression). Note that the $c^{d} t^{d b 7}$ mutant partially removes dmOAZ expression. j Proposed genetic cascade controlling spiracular chamber formation (cf. Hu and Castelli-Gair 1999; Hombria and Lovegrove 2003). DmOAZ appears to be a secondary target of $A b d-B$, downstream of the $c u t$ and ems. However, cut controls only a subset of $d m O A Z$-expressing cells. The hierarchical interactions between $d m O A Z$, trh and grh remain to be determined 
Because the posterior spiracle is the unique gas exchange site in first-instar larvae, we postulated that the spiracular mutant phenotype in $d m O A Z^{93}$ may cause a defective air entry. Indeed, we observed the tracheal system, and we found that the main tracheal branches are only partially filled with air in $d m O A Z^{93}$ mutants (Fig. 6f), whereas the air fills the entire tracheal system in the wild type (Fig. 6e).

To further characterize the spiracular defect in $d m O A Z^{93}$, we studied the staining patterns of the two reporter lines ems-Gal4, UAS-GFP, and grh-D4-lacZ that label subsets of spiracular chamber cells (see above). Yet, at embryonic stages 11 to 17, we did not observe any changes in these cells (concerning their shape or position) in homozygous dmOAZ ${ }^{93}$ mutant background compared to wild-type background (Fig. 6g 1,h 1 with g 2,h 2, respectively). Hence, the spiracular chamber cells labeled by ems-Gal4, UAS-GFP, and $g r h$-D4-lacZ reporter lines develop normally in $d m O A Z^{93}$.

\section{Discussion}

In this paper, we focus on DmOAZ, the unique $D$. melanogaster homologue of the OAZ family and the first identified OAZ member in invertebrates. Given that the two-dimensional protein structure of DmOAZ is largely conserved compared to its vertebrate counterparts, we propose Drosophila as a new model for studying the function of OAZ proteins. A useful tool will be the newly isolated $d m O A Z^{93}$ null allele, allowing to study the genetic interactions of OAZ in vivo. Moreover, we found that DmOAZ plays a role in the development of the posterior spiracle, a model organ for investigating the genetic basis of tissue morphogenesis.

As members of the superfamily of $\mathrm{C}_{2} \mathrm{H}_{2} \mathrm{ZF}$ transcription factors, OAZ proteins are able to interact with either DNA, RNA, and/or protein, depending on which clusters of ZFs are used (Iuchi 2001). The 21 ZF motifs of DmOAZ are arranged in four clusters comparable to their vertebrate counterparts. Are the functions of these four clusters conserved between the different members? The ZFs 1-3 of DmOAZ have a very high identity score $(67$ to $83 \%)$, suggesting that the $\mathrm{N}$-terminal ZFs 1-3 in DmOAZ could also be involved in DNAbinding, similar to the corresponding OAZ ZFs 2-4. However, further experiments designed to test possible cluster interactions and DNA-and protein-binding capacities are required to confirm this hypothesis. Moreover, a systematic screen should be performed to determine possible partners of DmOAZ in D. melanogaster cDNA libraries. This would allow to further elucidate the functions of DmOAZ.
By remobilizing the transposable $\mathrm{P}[\mathrm{GawB}]$ of GH146Gal4 (Stocker et al. 1997; Heimbeck et al. 2001), which is located just 280 bp upstream of the DmOAZ start codon, we created a number of mutant lines. From an initial 180 strains, no viable mutation in $d m O A Z$ was recovered, arguing that this locus plays an important role in viability. By genomic analysis and complementation test, we deduced that in the mutant characterized in more detail, $d m O A Z^{93}$, exclusively the $d m O A Z$ locus is affected by the $\mathrm{P}$ excision. Moreover, we determined by in situ hybridization, by RT-PCR, and by testing larval lethality of $d m O A Z^{93}$ over a deficiency that this allele represents a loss-of-function mutation.

The posterior spiracle is crucial for respiration, in particular during the first and second larval instars, when it is the only functional site for gas exchange. Our data show that the filzkörper morphology is defective in the $d m O A Z^{93}$ mutant, and we also observed that the air does not completely fill the main tracheal branches. None of the other posterior spiracle mutants ( $\mathrm{sal}$, ct, ems, grh, and trh mutants) exhibit comparable filzkörper phenotypes. We thus propose that the $d m O A Z$ gene is implicated in shaping this structure. Our data suggest that in the genetic cascade of posterior spiracle development (Hombria and Lovegrove 2003), dmOAZ is acting downstream of $c t$ and ems. The proteins encoded by the three genes are co-localized in subsets of spiracular chamber cells. Hence, Ct and Ems transcription factors could interact either directly or indirectly with DmOAZ. Moreover, both grh and trh mRNA show wild-type localization in the $d m O A Z^{93}$ mutant, suggesting that DmOAZ does not act upstream the grh and trh genes. Therefore, we postulate that DmOAZ on the one hand and Grh and Trh on the other act independently of each other in posterior spiracle development, at the same level of the cascade (Fig. 6j).

The posterior spiracles can be considered an interesting model for morphogenesis. They are easy to observe, and the two cell populations comprising this structure are formed by two different morphogenetic mechanisms $(\mathrm{Hu}$ and Castelli-Gair 1999). The inner cells develop into the spiracular chamber by a process of invagination and elongation, whereas the surrounding cells give rise to the stigmatophore by changing their relative positions. Each cell population requires different genes, all of which are early targets of $A b d-B$. We did not observe any changes concerning the elongation or invagination of the cells labeled by the two reporter lines grh-D4-lacZ and emsGal4, UAS-GFP, suggesting that DmOAZ does not act on shaping these groups of cells. However, we cannot exclude that DmOAZ plays a role in the elongation and/or invagination of other cells that take part in posterior spiracle development, as the patterns of the used reporter lines do not overlap completely with DmOAZ-expressing cells. 
The Smad-bone morphogenetic proteins (BMP) signaling pathway in D. melanogaster is involved in the regulation of numerous fundamental processes (Hogan 1996). Furthermore, signal transduction in the Smad-BMP pathway is conserved between vertebrates and invertebrates. A well-known member of the BMP signaling pathway in the fruit fly is represented by the morphogen Decapentaplegic (Dpp). Interestingly, hypomorphic $d p p$ mutants show an abnormal or even missing filzkörper (Wharton et al. 1993). Because an interaction between OAZ and BMP was shown in vertebrates and because the Smad-binding domains are conserved in DmOAZ, we suggest a possible interaction between DmOAZ and Dpp in the morphogenesis of the filzkörper. Such an interaction could be achieved either at the Smad step by a protein-protein interaction, and/or at the DNA level mediated by a BMP response element domain in the promoter region of Dpp-target genes.

The first identified member of the Olf/EBF family was shown to be implicated in the differentiation of the mammalian olfactory epithelium (Olf-1; Wang and Reed 1993) and of B-lymphocytes (EBF; Hagman et al. 1993). Crozatier et al. (1996) identified the Olf/EBF homologue of D. melanogaster and termed this family of transcription factors the Collier/Olf/EBF (COE) family. An association between COE and OAZ (indicated by the terminology: Olf/ EBF-associated $z$ inc finger protein) was proposed in several studies (Hata et al. 2000; Tsai and Reed 1997, 1998). Collier is the unique fruit fly member of the COE family with a structure highly conserved with mammalian COE. Although we did not find conservation between the entire OAZ cluster E (Olf/EBF-binding domain) and DmOAZ (ZFs 19-21), we observed correct alignment of the ZFs 19 and 21 on the OAZ cluster E. Hence, it will now be very interesting to test a possible interaction between DmOAZ and Collier.

Acknowledgment This work was supported by the Swiss National Funds (grants No. 3100A0-105517 [RFS] and 3234-069273.02 [AR]), Roche Research Foundation, and Fondation Aetas. We are very grateful to Dr. James Castelli-Gair (Centro Andaluz de Biologia del Desarrollo, Universidad Pablo de Olavide, Spain) for providing numerous $D$. melanogaster strains. We also thank Dr. L.-F. Bersier (Université de Fribourg) for help with statistics and survival analysis, Dr. G. Heimbeck for advice, and J. Meuwly and S. Vuichard for complementation tests.

\section{References}

Adams MD et al (2000) The genome sequence of Drosophila melanogaster. Science 287:2185-2195

Blochlinger K, Bodmer R, Jan LY, Jan YN (1990) Patterns of expression of cut, a protein required for external sensory organ development in wild-type and cut mutant Drosophila embryos. Genes Dev 4:1322-1331
Bray SJ, Kafatos FC (1991) Developmental function of Elf-1: an essential transcription factor during embryogenesis in Drosophila. Genes Dev 5:1672-1683

Brown S, Castelli-Gair Hombria J (2000) Drosophila grain encodes a GATA transcription factor required for cell rearrangement during morphogenesis. Development 127:4867-4876

Campos-Ortega JA, Hartenstein V (1997) The embryonic development of Drosophila melanogaster. Springer, Berlin Heidelberg New York

Castelli-Gair JE, Greig S, Micklem G, Akam ME (1994) Dissecting the temporal requirements for homeotic gene function. Development 120:1983-1995

Chang HCY, Solomon NM, Wassarman DA, Karim FD, Therrien M, Rubin GM, Wolff T (1995) Phyllopod functions in the fate determination of a subset of photoreceptors in Drosophila. Cell $80: 463-472$

Crozatier M, Valle D, Dubois L, Ibnsouda S, Vincent A (1996) Collier, a novel regulator of Drosophila head development, is expressed in a single mitotic domain. Curr Biol 6:707-718

Dalby B, Pereira, AJ, Goldstein LSB (1995) An inverse PCR screen for the detection of $\mathrm{P}$ element insertions in cloned genomic intervals in Drosophila melanogaster. Genetics 139:757-766

Dalton D, Chadwick R, McGinnis W (1989) Expression and embryonic function of empty spiracles: a Drosophila homeo box gene with two patterning functions on the anterior-posterior axis of the embryo. Genes Dev 3:1940-1956

Dickson BJ, Dominguez M, van der Straten A, Hafen E (1995) Control of Drosophila photoreceptor cell fates by phyllopod, a novel nuclear protein acting downstream of the Raf kinase. Cell $80: 453-462$

Hagman J, Belanger C, Travis A, Turck CW, Grosschedl R (1993) Cloning and functional characterization of early B-cell factor, a regulator of lymphocyte-specific gene expression. Genes Dev $7: 760-773$

Hata A, Seoane J, Lagna G, Montalvo E, Hemmati-Brivanlou A, Massague J (2000) OAZ uses distinct DNA- and protein-binding zinc fingers in separate BMP-Smad and Olf signaling pathways. Cell 100:229-240

Heimbeck G, Bugnon V, Gendre N, Keller A, Stocker F (2001) A central neural circuit for experience-independent olfactory and courtship behavior in Drosophila melanogaster. Proc Natl Acad Sci USA 98:15336-15341

Hogan BL (1996) Bone morphogenetic proteins in development. Curr Opin Genet Dev 6:432-438

Hombria JC, Lovegrove B (2003) Beyond homeosis-HOX function in morphogenesis and organogenesis. Differentiation 71:461-476

$\mathrm{Hu}$ N, Castelli-Gair J (1999) Study of the posterior spiracles of Drosophila as a model to understand the genetic and cellular mechanisms controlling morphogenesis. Dev Biol 214:197-210

Isaac DD, Andrew DJ (1996) Tubulogenesis in Drosophila: a requirement for the trachealess gene product. Genes Dev 10:103-117

Iuchi S (2001) Three classes of $\mathrm{C} 2 \mathrm{H} 2$ zinc finger proteins. Cell Mol Life Sci 58:625-635

Jones B, McGinnis W (1993) The regulation of empty spiracles by abdominal-B mediates an abdominal segment identity function. Genes Dev 7:229-240

Jürgens G (1985) A group of genes controlling the spatial expression of the bithorax complex in Drosophila. Nature 316:153-155

Klein T, Campos-Ortega JA (1997) klumpfuss, a Drosophila gene encoding a member of the EGR family of transcription factors, is involved in bristle and leg development. Development 124:3123-3134

Knight RD, Shimeld SM (2001) Identification of conserved C2H2 zinc-finger gene families in the bilateria. Genome Biol 2: RESEARCH0016 
Ku MC, Stewart S, Hata A (2003) Poly(ADP-ribose) polymerase 1 interacts with OAZ and regulates BMP-target genes. Biochem Biophys Res Commun 311:702-707

Kuhnlein RP, Frommer G, Friedrich M, Gonzalez-Gaitan M, Weber A, Wagner-Bernholz JF, Gehring WJ, Jäckle H, Schuh R (1994) spalt encodes an evolutionarily conserved zinc finger protein of novel structure which provides homeotic gene function in the head and tail region of the Drosophila embryo. EMBO J 13:168-179

Lamka ML, Boulet AM, Sakonju S (1992) Ectopic expression of UBX and ABD-B proteins during Drosophila embryogenesis: competition, not a functional hierarchy, explains phenotypic suppression. Development 116:841-854

Letunic I, Copley RR, Schmidt S, Ciccarelli FD, Doerks T, Schultz J, Ponting CP, Bork P (2004) SMART 4.0: towards genomic data integration. Nucleic Acids Res 32:D142-144

Manning G, Krasnow MA (1993) Development of the Drosophila tracheal system. In: Bate M, Martinez Arias A (eds) The development of Drosophila melanogaster, vol 1. Cold Spring Harbor Lab Press, pp. 609-685

Merabet S, Hombria JC, Hu N, Pradel J, Graba Y (2005) Hoxcontrolled reorganisation of intrasegmental patterning cues underlies Drosophila posterior spiracle organogenesis. Development 132:3093-3102

Ng M, Diaz-Benjumea FJ, Cohen SM (1995) nubbin encodes a POUdomain protein required for proximal-distal patterning in the Drosophila wing. Development 121:589-599

Patel NH, Martin-Blanco E, Coleman KG, Poole SJ, Ellis MC, Kornberg TB, Goodman CS (1989) Expression of engrailed proteins in arthropods, annelids, and chordates. Cell 58:955-968

Sanchez-Herrero E, Vernos I, Marco R, Morata G (1985) Genetic organization of Drosophila bithorax complex. Nature 313:108113

Schultz J, Milpetz F, Bork P, Ponting CP (1998) SMART, a simple modular architecture research tool: identification of signaling domains. Proc Natl Acad Sci USA 95:5857-5864

Schüpbach T, Wieschaus E (1991) Female sterile mutations on the second chromosome of Drosophila melanogaster. II. Mutations blocking oogenesis or altering egg morphology. Genetics 129:1119-36

Shim S, Bae N, Han JK (2002) Bone morphogenetic protein-4induced activation of Xretpos is mediated by Smads and Olf-1/
EBF associated zinc finger (OAZ). Nucleic Acids Res 30:31073117

Stocker RF, Heimbeck G, Gendre N, de Belle JS (1997) Neuroblast ablation in Drosophila P[GAL4] lines reveals origins of olfactory interneurons. J Neurobiol 32:443-456

Tautz D, Pfeifle C (1989) A non-radioactive in situ hybridization method for the localization of specific RNAs in Drosophila embryos reveals translational control of the segmentation gene hunchback. Chromosoma 98:81-85

Thompson JD et al (1994) CLUSTAL W: improving the sensitivity of progressive multiple sequence alignment through sequence weighting, position-specific gap penalties and weight matrix choice. Nucleic Acids Res 22:4673-4680

Tsai RY, Reed RR (1997) Cloning and functional characterization of Roaz, a zinc finger protein that interacts with $\mathrm{O} / \mathrm{E}-1$ to regulate gene expression: implications for olfactory neuronal development. J Neurosci 17:4159-4169

Tsai RY, Reed RR (1998) Identification of DNA recognition sequences and protein interaction domains of the multiple-Zn-finger protein Roaz. Mol Cell Biol 18:6447-6456

Walldorf U, Gehring WJ (1992) Empty spiracles, a gap gene containing a homeobox involved in Drosophila head development. EMBO J 11:2247-2259

Wang MM, Reed RR (1993) Molecular cloning of the olfactory neuronal transcription factor Olf-1 by genetic selection in yeast. Nature 364:121-126

Warming S, Liu P, Suzuki T, Akagi K, Lindtner S, Pavlakis GN, Jenkins NA, Copeland NG (2003) Evi3, a common retroviral integration site in murine B-cell lymphoma, encodes an EBFAZrelated Krüppel-like zinc finger protein. Blood 101:1934-1940

Warming S, Suzuki T, Yamaguchi TP, Jenkins NA, Copeland NG (2004) Early B-cell factor-associated zinc-finger gene is a frequent target of retroviral integration in murine B-cell lymphomas. Oncogene 23:2727-2731

Wharton KA, Ray RP, Gelbart WM (1993) An activity gradient of decapentaplegic is necessary for the specification of dorsal pattern elements in the Drosophila embryo. Development 117:807-822

Whitten J (1980) The tracheal system. In: Ashburner M, Wright TRF (eds) The genetics and biology of Drosophila, vol 2d. Academic, London, 499-540 